\title{
Latitudinal and environmental patterns in abundance and composition of epilithic microphytobenthos
}

\author{
A. C. Jackson ${ }^{1,4}$, A. J. Underwood ${ }^{1}$, R. J. Murphy ${ }^{2}$, G. A. Skilleter ${ }^{3}$ \\ ${ }^{1}$ Centre for Research on Ecological Impacts of Coastal Cities, Marine Ecology Laboratories, A11, and \\ ${ }^{2}$ Australian Centre for Field Robotics, The Rose Street Building J04, Department of Aerospace, Mechanical \& Mechatronic \\ Engineering, University of Sydney, New South Wales 2006, Australia \\ ${ }^{3}$ Marine and Estuarine Ecology Unit, School of Biological Sciences (Goddard Bldg), University of Queensland, Brisbane, \\ Queensland 4072, Australia \\ ${ }^{4}$ Present address: Environmental Research Institute, Castle Street, Thurso, Caithness KW14 7JD, UK
}

\begin{abstract}
Epilithic microphytobenthos (EMPB) is of core importance in intertidal assemblages and responds to a variety of environmental variables, including season, light, temperature and exposure to waves. To help understand responses by EMPB to these variables and their interactions, EMPB was compared at 2 different latitudes in eastern Australia. In subtropical Brisbane and temperate Sydney, EMPB was sampled at 4 different heights on shores exposed to, or sheltered from, waves during the austral winters and summers of 2006 to 2008. Trends of increasing biomass with decreasing height on shore supported previous studies. In particular, the interaction between season and height was similar to results of previous studies in Australia. There were no differences in biomass of standing stock between Sydney and Brisbane. Differences in timing of sampling occasions confounded some comparisons, and some observed patterns may be due to differences in rates of recolonisation among treatments. Spectrometric assessment of the composition of pigments in EMPB differed with latitude. Spectral samples were more similar to those from assemblages of cyanobacteria than to assemblages of green algae, and this was more marked in Sydney than in Brisbane. Amounts of chlorophyll a were greater on sheltered shores than on those exposed to waves. These patterns are not easily explained, but serve to illustrate the difficulties of extrapolating patterns and processes from one area to another. Variations in pattern at different heights on the shore and in different years emphasise the need for spatially and temporally extensive data in order to make reliable predictions about EMPB. Improved capacity to make reliable predictions will help us understand how EMPB may respond to our changing climate, which is forecast to be hotter with more frequent storms.
\end{abstract}

KEY WORDS: Geographic distribution - Micro-algae - Temperature - Diatoms - Cyanobacteria · Grazing $\cdot$ Climatic change

\section{INTRODUCTION}

Global climatic change will cause major alterations to important environmental variables (IPCC 2007). On rocky shores, components likely to affect species directly include increases in mean temperatures of air and water, frequencies of extremely high temperatures and more frequent intense storms (CSIRO 2007, IPCC 2007).

Epilithic microphytobenthos (EMPB) is ecologically important in many aquatic habitats and is a vital component of assemblages of species on rocky intertidal 
areas. It makes important contributions to primary production (Yallop et al. 1994), provides food for many grazers (Underwood 1979, 1984a, Hawkins \& Hartnoll 1983, Hawkins et al. 1992, Thompson et al. 2004) and influences settlement of the dispersive larvae of many sessile invertebrates (e.g. barnacles, oysters) (Keough \& Raimondi 1995, 1996, Thompson et al. 1998, Wieczorek \& Todd 1998). Amounts of EMPB are also often positively related to numbers and growth of grazers (Castenholz 1961, Underwood 1984a, Bustamante et al. 1995), although a history of grazing can suppress biomass of EMPB long after removal of grazers (Skov et al. 2010). Biomass of EMPB can also influence ecological interactions among grazers (e.g. competition: Haven 1973, Underwood et al. 1983, Underwood 1984b; facilitation: Underwood \& Murphy 2008). Consequently, differences in intensity of grazing affect settlement and growth of macro-algae, for example, by consumption of sporelings and germlings (reviewed in Hawkins \& Hartnoll 1983).

Distributions and abundances of EMPB have been studied in cool as well as in warm temperate intertidal systems (Castenholz 1961, Nicotri 1977, Underwood 1984c, MacLulich 1986, Hill \& Hawkins 1990, Jenkins et al. 2001, Thompson et al. 2005), but less is known from tropical or subtropical areas (Mak \& Williams 1999, Nagarkar \& Williams 1999). Growth of EMPB is often limited by excessive temperatures or light (Underwood 1984c, Ruban \& Horton 1995, Thompson et al. 2004), so amounts of EMPB are likely to be smaller on tropical than on temperate shores; however, to our knowledge, there have been no comparative studies other than comparisons of chlorophyll a (chl a) spanning cool to warm temperate shores in Europe (Jenkins et al. 2001).

Abundances of EMPB are typically greater in winter than in summer (Underwood 1984c, Dye \& White 1991, Hill \& Hawkins 1991, Jenkins \& Hartnoll 2001), greater lower than higher on the shore (Castenholz 1963, Underwood 1984c, Dye \& White 1991) and can be greater on wave-exposed than on sheltered shores (Thompson et al. 2004, 2005), or, when numbers of grazers are controlled for, greater on sheltered than on wave-exposed shores (Jenkins \& Hartnoll 2001). Studies on rocky shores concerning variation in compositions of assemblages of EMPB in response to environmental variables are rare. For example, diatoms can be more abundant lower on the shore (Castenholz 1963) and decrease with increasing insolation (Thompson et al. 2004), and cyanobacteria are relatively more abundant during the 'extreme' conditions of a tropical summer (Nagarkar \& Williams 1999). The variety of types of EMPB can be greatest in summer (MacLulich 1987). Other studies have investigated how the composition of EMPB is affected by grazing (Nicotri 1977, Hawkins et al. 1989,
Kaehler \& Froneman 2002), grazing history (Skov et al. 2010), or succession (MacLulich 1986). Comprehensive studies on how different conditions affect compositions of micro-algae on rocky shores in different climatic regions have not yet been done.

To understand the consequences of different temperatures and exposures to waves, we used field spectrometry to estimate distributions, amounts and types of EMPB over 2 yr for different seasons, exposures to waves and heights on the shore, in a warm temperate area (Sydney) and in a subtropical area (Brisbane) . We predicted: (1) greater biomass of the EMPB in Sydney than in Brisbane; (2) more algae during cool than during warm seasons; (3) more EMPB lower than higher on the shore; and (4) that effects of latitude, season, exposure to waves and height on the shore would interact to influence biomass of EMPB. For example, differences in amounts of chl a among heights on the shore would be less pronounced during summer than during winter (as in Underwood 1984c); the strength of this interaction could be influenced in either direction by exposure to waves (because of differences in temperature, amounts of moisture caused by wave-splash, or the presence of other algae; e.g. Thompson et al. 2005). We also predicted: (5) that assemblages of EMPB would be more dominated by cyanobacteria in Brisbane than in Sydney, during summer than winter and higher than lower on the shore; (6) that diatoms would be relatively more abundant lower than higher on the shore; and (7) that differences in exposure to waves would influence how types of EMPB are affected by height and season (e.g. Thompson et al. 2005). Predictions such as these, based on experiments, are vital if we are to understand the ecological consequences of climatic change.

\section{MATERIALS AND METHODS}

Study location. Rocky shores were studied in 2 climatic regions on the east coast of Australia; the subtropical Sunshine Coast in Queensland and the warmtemperate area around Sydney (Fig. 1). In each region, over a 2 yr period (2006 to 2008), we sampled EMPB on 2 shores exposed to waves and 2 sheltered shores during the austral winter (July and August) and summer (January to March). Exposed or sheltered shores were on opposite sides of rocky headlands. Exposed shores faced the prevailing direction (south-easterly) of swell, whereas sheltered shores did not or were protected by an offshore reef.

The grazing gastropods Nerita atramentosa, Cellana tramoserica, Austrocochlea porcata and Bembicium nanum are common to both regions and are the dominant animals on rocky shores, where they inhabit most 


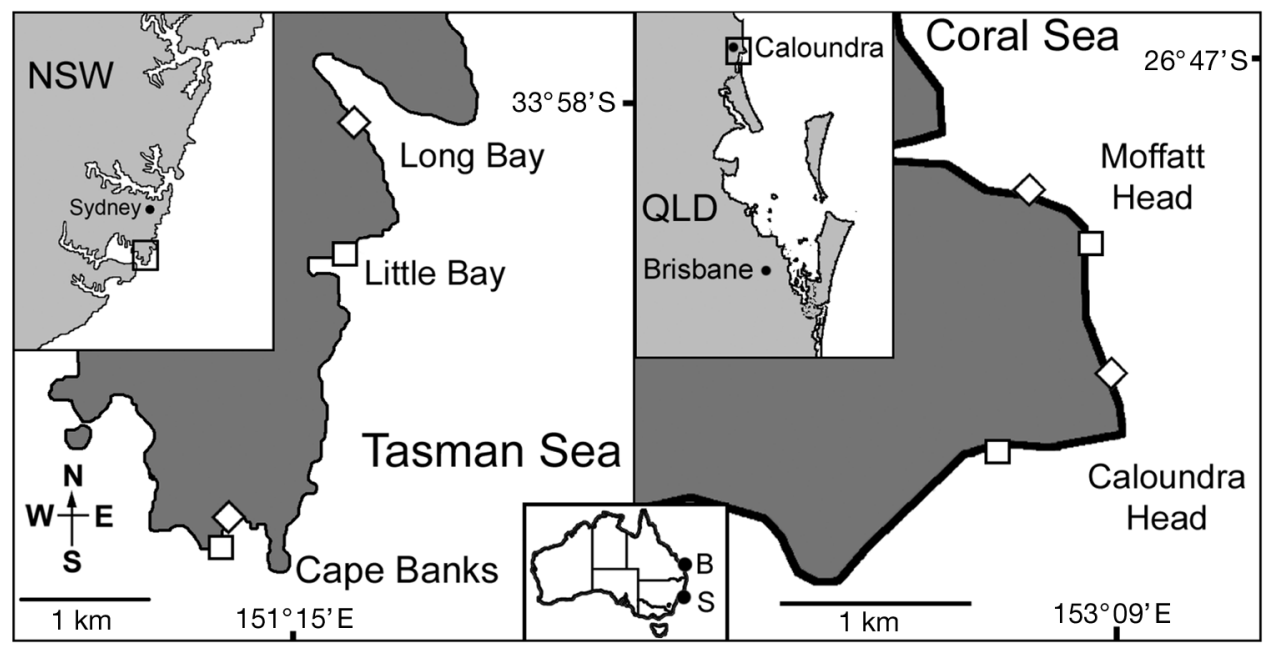

Fig. 1. Four locations at each of 2 different latitudes (temperate: Sydney [S], New South Wales [NSW]; subtropical: Brisbane [B], Queensland [QLD]) at which biofilms were measured. Locations were exposed to ( $\square$ ) or sheltered from $(\diamond)$ the prevailing direction of swell (south-easterly)

of the tidal range and eat EMPB. To understand patterns in EMPB where it is an important resource, the vertical range of each shore inhabited by these gastropods was divided into 5 bands of equal horizontal width (1: upper shore; 5 : lower shore). Mean elevations above the zero tide level of these bands were surveyed in relation to benchmarks of known elevation.

Sampling EMPB. Recent developments in methods for measuring EMPB, especially colour-infrared imaging (Murphy et al. 2004, 2006) and field spectrometry (Murphy et al. 2005) have revolutionised the nature, scope and scale of studies. Field spectrometry provides non-destructive estimates of biomass of EMPB. Chl $a$, the main photosynthetic pigment in EMPB, is used as a proxy for biomass of EMPB and for numbers of algal cells, because chl a absorbs red light strongly and there is often a linear relationship between this absorbance and the amount of chl a (Underwood 1984c, Murphy et al. 2006, 2009). Because different kinds of EMPB (e.g. diatoms, cyanobacteria, green micro-algae) contain different combinations of pigments, field spectrometry also provides information about the composition of assemblages (chemotaxonomy; Jeffrey et al. 1997).

Estimating amounts of chl a. Quantifying chl $a$ in EMPB is potentially difficult, because it is present in small quantities and chl $a$ is also present in encrusting macro-algae, which do not constitute a primary foodsource for many grazers (Underwood 1984c), although there are some specialists (e.g. Steneck 1982, Hawkins et al. 1989). To obtain estimates solely of EMPB, measurements were made in patches $(300 \times 300 \mathrm{~mm})$ cleared of all flora and sessile fauna using wire scrubbing-brushes and dilute hydrochloric acid (Underwood 1984c, Murphy et al. 2006). Such cleared space is recolonised by EMPB, densities of which have been shown to increase during the first 4 wk after clearing and remaining fairly constant afterwards (Underwood 1984c, MacLulich 1986, Murphy et al. 2006). Estimates of chl a from the first sampling occasion (winter 2006) indicated that, contrary to expectations, except on the very lowest shore, there was very little EMPB $4 \mathrm{wk}$ after scrubbing; thus, patches were subsequently sampled after 6 to $8 \mathrm{wk}$. Five different randomly chosen patches were cleared at each of the upper 4 bands for each time of sampling. Different patches were used each time to ensure that data were independent.

Spectrometry. We estimated amounts and types of EMPB from reflectance spectra using a field spectrometer (FieldSpec Pro, Analytical Spectral Devices). For calibration, prior to each measurement from the rock, a spectrum was taken from a reflectance standard ( 99\% Spectralon). Each spectrum from the rock was then divided by the spectrum of the reflectance standard to produce a reflectance spectrum in which effects associated with the solar irradiance curve and atmosphere are removed. In each patch, 5 replicate spectra were measured using a bare optical fibre at a height of $110 \mathrm{~mm}$, sampling an area about $50 \mathrm{~mm}$ in diameter. The 5 measures were averaged to estimate the EMPB in each patch. In most cases, foliose macroalgae did not colonise the patches before measurement, but the few patches with visible macro-algae were excluded from analysis. In the lowest band of the shore, growth of macro-algae was very prolific, so EMPB could not be sampled.

Absorptions by some pigments are weak or are overlapping, and substrata can vary greatly in brightness. To compare spectra acquired from different areas at different times and to enhance subtle absorptions by pigments, all spectra were placed on the same plane of 
reference using spectral derivative analysis. Because assemblages of EMPB and their rocky substrata often differed between Sydney and Brisbane, this form of analysis is more appropriate than are vegetation indices, which are often used to estimate amounts of chl a. Fourth-derivative spectra were calculated from pseudo-absorbance $[\log (1 /$ reflectance $)]$ spectra using combined differentiation and smoothing (Savitzky \& Golay 1964, Steinier et al. 1972) with a $30 \mathrm{~nm}$ smoothing window. Each absorption feature in the spectrum is shown as a peak above the zero baseline of the derivative, the height of which is indicative of the relative amount of absorption made by the pigment causing that absorption. Relative amounts of absorption by pigments are thus calculated as the maximal derivative reflectance of each peak.

Amounts of chl a (as an index of biomass of EMPB) were estimated from fourth-derivative spectra, using the height of the chl a peak (at $\sim 680 \mathrm{~nm}$ ) above the zero baseline. As a test of the methodology, the height of the chl a peak was compared with chemical estimates of amounts of chl a. EMPB was grown on sandstone disks $(5.8 \mathrm{~cm}$ diameter placed on the rocky shore at Cape Banks [Fig. 1] during September and October 2005 for different periods of time to ensure a good range of biomass). Reflectance spectra were acquired from the surface of each disk. The amount of chl $a$ on each disk was determined by extraction using cold methanol followed by spectrophotometric analysis (Thompson et al. 1999). The relationship between the height of the fourth-derivative peak at $\sim 680 \mathrm{~nm}$ and the amount of chl $a$ was examined by linear regression.

Shores were not always smoothly sloping, and, within individual bands, there could be considerable variation in elevation. To investigate associations between EMPB and elevation, amounts of chl a were correlated against height for each patch. Amounts of chl a were compared among latitudes, seasons, years, locations, exposure to waves and height on the shore using ANOVA. To understand better the differences in amounts of chl $a$ at different heights on the shore, the magnitudes of differences between upper and lower heights (Height 4 minus Height 1) were also analysed using ANOVA for latitude, seasons and locations (random, 3 levels), $\mathrm{n}=5$ differences. Post hoc pairwise comparisons (Student-Newman-Keuls [SNK] tests) were done to understand patterns of differences in significant interactions. Where there were numerous possible comparisons, binomial tests were used to investigate whether the observed frequency of differences in a particular direction differed significantly from that expected if differences in either direction were equally likely $(p=0.5)$.

EMPB is often limited by excess heat or light, so we estimated the correlation between mean amounts of $\mathrm{chl} a$ for each latitude on each sampling occasion with the: (1) mean daily solar exposure $\left(\mathrm{MJ} \mathrm{m}^{-2}\right)$, (2) mean maximal air temperature $\left({ }^{\circ} \mathrm{C}\right)$ and $(3)$ greatest air temperature for the previous month. Values for solar exposure and temperatures for each month and latitude were obtained from the Australian Bureau of Meteorology website. Mean daily solar exposure is the solar energy reaching a specific location on the Earth's surface during a month and was estimated by the bureau from geostationary meteorological satellite data.

Composition of pigments in EMPB. Relative amounts of absorption by pigments: The pigment causing each absorption peak was identified by comparing the wavelength position of maximal absorbance to published wavelengths of absorption by pigments in vivo. Five pigments were selected to separate different types of EMPB: carotenoids ( 493 nm), phycoerythrocyanin $(\sim 574 \mathrm{~nm})$, chlorophyll $c(\sim 636 \mathrm{~nm})$, chlorophyll $b(\sim 651 \mathrm{~nm})$ and chlorophyll a $(\sim 680 \mathrm{~nm})$. Comparisons among amounts of pigments must be standardised to account for differences in total amounts of EMPB among samples; thus, amounts of pigments in each sample were normalised relative to the amount of $\mathrm{chl} a$ (which is a reliable estimator of the amount of EMPB; see previous subsection) in that sample. Relative amounts of the 4 normalised pigments were analysed as multivariate data using PERMANOVA (Anderson 2001) and SIMPER (Clarke \& Warwick 2001) to make comparisons among samples.

Comparison with known spectra: Types of EMPB may also be identified by comparing an unknown spectrum to that of assemblages of known composition. Using the whole spectral curve includes information about pigments, which are omitted by extracting data at single wavelengths (as above). Spectra were taken from assemblages composed only of either diatoms or cyanobacteria (as functional groups) grown on sandstone slabs in an aquarium. Each type of EMPB was independently identified using confocal laser scanning microscopy. A spectrum for green microalgae was also obtained from naturally occurring dense films of green micro-algae on the shore; these showed a distinct peak in the green part of the spectrum $(\sim 550 \mathrm{~nm})$ and had large amounts of absorption due to chlorophyll $b$ at $\sim 651 \mathrm{~nm}$. A spectral library was created that included spectra from the 3 algal groups and also from bare rock. All spectra sampled in the field were compared, in turn, with the library spectra.

Fourth-derivative spectra were then calculated for all unknown and all library spectra. For each unknown spectrum, a subset of wavelengths (between 550 and $710 \mathrm{~nm}$ ), which includes absorption peaks from all the important discriminatory pigments was compared with the same subset from each library spectrum using the method described in Kirkpatrick et al. (2000). This pro- 
vides an index of similarity (SI), which describes how well each unknown spectrum matches a library spectrum. An SI of 1 means that spectra are a perfect match; an SI of zero means there is no similarity.

\section{RESULTS}

\section{Index for chl a}

There was a strong linear relationship between the height of the derivative peak at $\sim 680 \mathrm{~nm}$ and the amounts of chl a extracted in the laboratory (chl $a=$ $3.008 \times$ derivative peak +0.007$) ; \mathrm{r}^{2}=0.93, \mathrm{SE}=0.14$, $\mathrm{p}<0.0001, \mathrm{n}=31$ ), indicating that the former is an accurate measure of the amount of chl $a$.

\section{Amounts of chl a}

Amounts of chl a, used as a proxy for amounts of EMPB, varied spatially and temporally, but not always in the patterns predicted. Analyses were complicated by 2 considerations. First, during winter of the first year, shores were sampled after a shorter interval ( $4 \mathrm{wk}$ ) following scraping than on later occasions (6 to $8 \mathrm{wk}$ ). This may have been due to temporal variability in conditions, but, subsequently, patches were sampled 6 to 8 wk after scrubbing. After this time, EMPB may still have been recovering rather than being a mature assemblage, although amounts of EMPB were within the range typical for these shores (up to $1.5 \mu \mathrm{g} \mathrm{cm}^{-2}$; Murphy et al. 2006, Jackson et al. 2009). Second, a fully balanced design was not achieved because, on some occasions, patches or heights could not be sampled because of overlying sand (uppermost height at 1 location) or unfavourable weather conditions (lower shore).

To maximise the amount of data used for interpretation 3 analyses were carried out. First, a 6-factor ANOVA was done including data from each latitude (fixed, Brisbane or Sydney), season (fixed, summer or winter), year (random, 1 or 2), waves (fixed, exposed or sheltered) and location (random, 2 levels nested in latitude and waves), but from only the middle heights (Levels 2 and 3 fixed, 2 levels), n = 4 replicate patches. Second, a 5-factor ANOVA (excluding waves) was done including latitude, year, season, location (random, 3 levels nested in latitude) and height (4 levels), $\mathrm{n}=3$ patches. The locations actually included were 1 exposed and 2 sheltered each in Sydney and in Brisbane. Third, a 5-factor ANOVA (excluding year and season) was done including latitude, occasion (random, 3 levels), waves, location (random, 2 levels nested in latitude and waves) and height (4 levels), $\mathrm{n}=4$ patches. One summer and 2 winters were included.

\section{Latitude}

In Analysis 1, there was a significant interaction in latitude $\times$ season $\times$ year $\times$ waves $\left(F_{1,192}=14.5, \mathrm{p}<\right.$ $0.001)$. In the first year, during each season and for each level of exposure, mean amounts of chl a were greater in Brisbane than in Sydney, but differences were only significant once (post hoc SNK tests; p < 0.05; Fig. 2). In the second year, there was more chl a in Sydney than in Brisbane in all 4 comparisons; 3 out of 4 of these were significant differences (Fig. 2).

\section{Season}

Comparisons were not made between summer and winter in Year 1 because of the different periods of time during which micro-algae were permitted to develop. In Year 2, there was a significant interaction in latitude $\times$ season $\times$ year $\times$ waves in Analysis 1 $\left(F_{1,192}=14.5, \mathrm{p}=<0.001\right)$, but post hoc SNK tests showed amounts of chl a were significantly greater in winter than in summer only for sheltered shores in Sydney (mean $\pm \mathrm{SE}, \mathrm{n}=16,0.269 \pm 0.02>0.159 \pm 0.01$, equivalent to $0.82 \pm 0.08$ and $0.49 \pm 0.02 \mu \mathrm{g} \mathrm{cm}^{-2} \mathrm{chl} a_{\text {, }}$ respectively).

In Analysis 2, which included all 4 heights from 3 locations at each latitude, there was a significant seasons $\times$ years $\times$ height interaction $\left(F_{3,12}=13.72\right.$, $\mathrm{p}<0.001)$. There was significantly more chl a in winter than in summer in all but Band 1 (the upper shore).

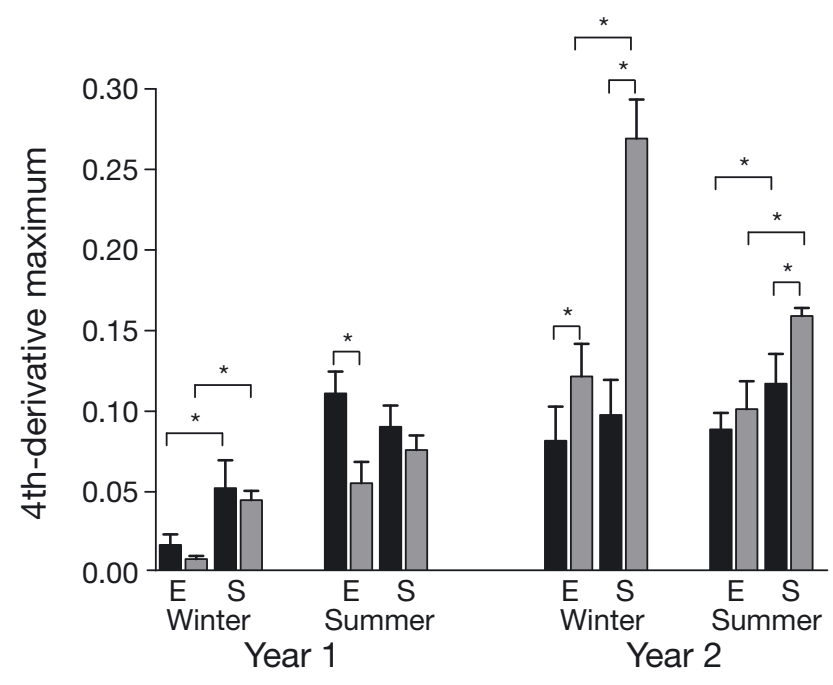

Fig. 2. Mean ( $\mathrm{SE}, \mathrm{n}=16$ patches) heights above the zero baseline of peaks of absorption by chlorophyll a (at $\sim 680 \mathrm{~nm}$ ) from fourth-derivative spectra of epilithic microphytobenthos. Black bars: Brisbane; grey bars: Sydney; E and S: locations exposed to or sheltered from prevailing swell, respectively; ${ }^{*}: \mathrm{p}<0.05$ (Student-Newman-Keuls test) 

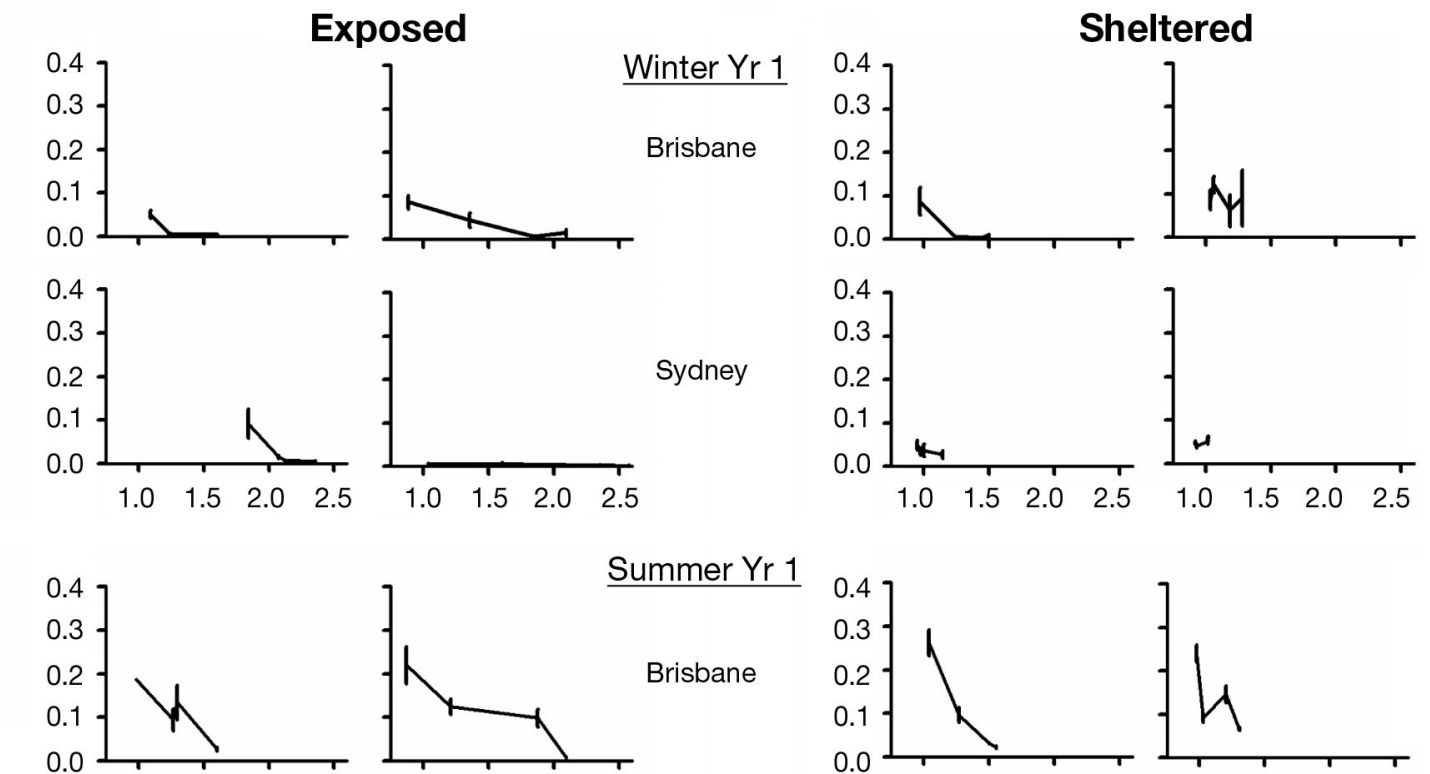

Summer Yr 1
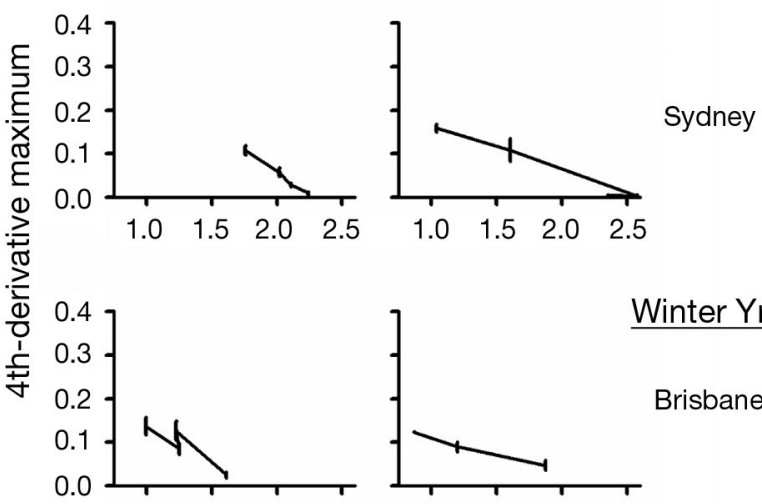

Brisbane
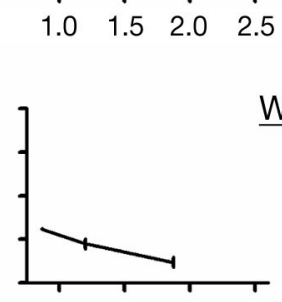

Winter Yr 2
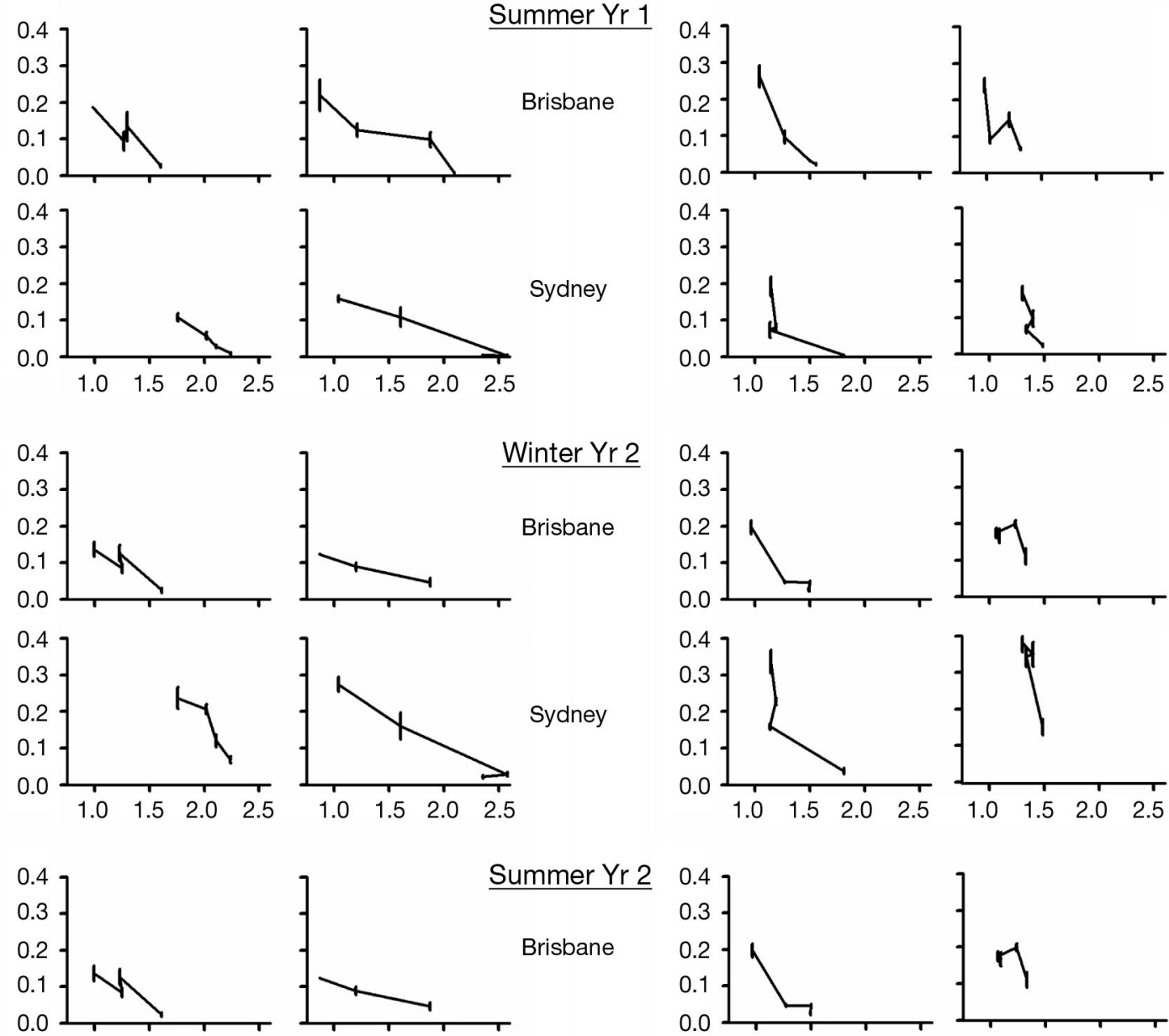

Summer Yr 2
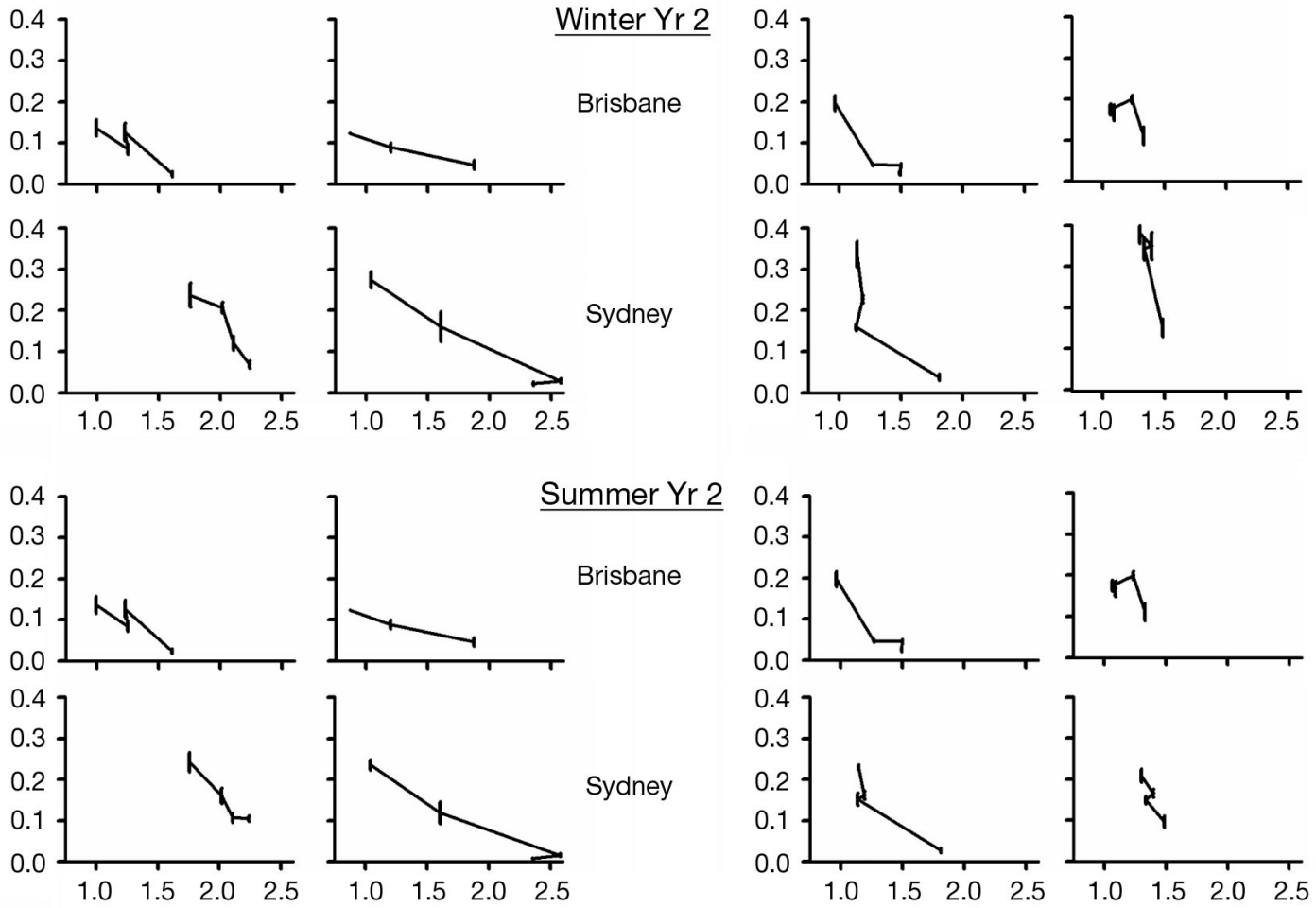

Height on shore $(\mathrm{m})$

Fig. 3. Mean (SE, $\mathrm{n}=5$ patches) heights above the zero baseline of peaks of absorption by chlorophyll $a$ (at $\sim 680 \mathrm{~nm}$ ) from fourthderivative spectra of epilithic microphytobenthos against mean heights above Chart Datum for 2 wave-exposed and 2 sheltered locations at each of 2 latitudes (Brisbane or Sydney) during different seasons and years 


\section{Exposure to waves}

There was more chl a on sheltered than on exposed shores in 7 of 8 comparisons in the latitude $\times$ season $\times$ year $\times$ waves interaction in Analysis 1; 5 of these comparisons were significant (Fig. 2). Seven out of 8 are significantly more frequent than expected if exposed or sheltered shores are equally likely to have most chl a (binomial test, $\mathrm{p}<0.05$ ), demonstrating that greater exposure to waves decreased chl a.

When all heights were considered on 3 occasions in Analysis 3, there was more chl a on sheltered than on exposed shores for 36 out of 48 comparisons, which is significantly more than expected by chance (binomial test, $\mathrm{p}<0.001$ and 15 of these pairwise comparisons were significant in SNK tests of the significant height $\times$ occasions $\times$ waves $\times$ places(latitude) interaction; $\left.F_{12,288}=3.92, \mathrm{p}<0.001\right)$.

\section{Height on the shore}

Amounts of chl a were negatively correlated with elevation ( $\mathrm{r}=-0.36, \mathrm{p}<0.001, \mathrm{n}=615)$; thus, amounts of chl a were greater on the low than on the high shore (Fig. 3). In Analysis 2, all pairwise comparisons of the significant height $\times$ years $\times$ locations(latitude) interaction $\left(F_{12,192}=2.36, \mathrm{p}=0.008\right)$ showed that there was more chl $a$ at the bottom than at the top of the shores (Fig. 4; binomial test, $\mathrm{p}<0.05$ ). Ten of these 12 comparisons were significant in SNK tests.

Similarly, in Analysis 3, there was more chl a at the bottom than the top in all of 24 comparisons of Heights 4 and 1 . This is significantly more frequent than random expectation (binomial test, $\mathrm{p}<0.001$ ). Nineteen of these 24 comparisons were significant in SNK tests of the significant height $\times$ occasions $\times$ waves $\times$ locations (latitude) interaction (see 'Exposure to waves' above).

There were complex interactions among all factors $\left(F_{4,96}=5.2, \mathrm{p}=<0.001\right)$ for differences in amounts of chlorophyll between upper and lower heights (Height 4 minus Height 1). As above, comparisons of years and of seasons from Year 1 were not done because of the different durations of micro-algal growth. During Year 2, there was no consistent effect of latitude or season on differences between Heights 4 and 1.

\section{Temperature and insolation}

Amounts of chl a were negatively related to mean daily solar exposure, mean maximal air temperature and to the greatest air temperature for the previous month, but the correlation was only significant ( $\mathrm{r}=$ $-0.78, \mathrm{n}=6, \mathrm{p}<0.05)$ for the last of these.

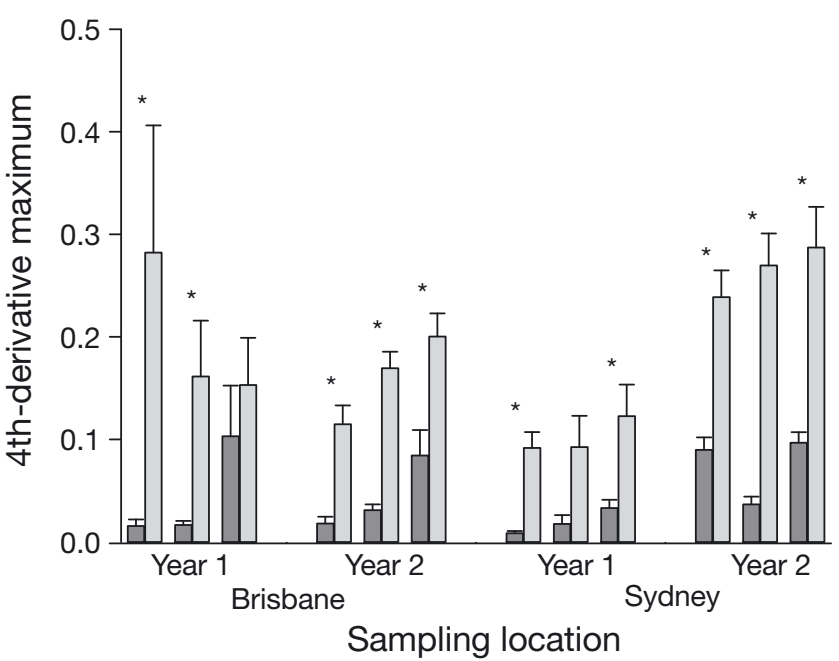

Fig. 4. Mean (SE, $\mathrm{n}=6$ patches) heights above the zero baseline of peaks of absorption by chlorophyll a (at $\sim 680 \mathrm{~nm}$ ) from fourth-derivative spectra of epilithic microphytobenthos (Analysis 2). Dark grey bars: Height 1 (upper shore); light grey bars: Height 4 (lower shore); *: p $<0.05$ (StudentNewman-Keuls test)

\section{Pigments and types of micro-algae}

Amounts of chlorophyll $c$ showed a weak, but significant, decrease with increasing elevation on the shore (correlation, $\mathrm{r}=-0.09, \mathrm{n}=624, \mathrm{p}<0.01$ ), but carotenoids, chlorophyll $b$ and phycoerythrocyanin showed no trends. Relative amounts of pigments from samples were then analysed, but there was no consistent effect of waves or height on the shore (Table 1).

The percentage contribution of different pigments to differences among samples (SIMPER; Clarke \& Warwick 2001) was examined for all factors. Phycoerythrocyanin consistently explained the largest percentage (38 to $41 \%$ ) of the difference among latitudes, seasons, exposure to waves, or heights on the shore. The 3 other pigments varied inconsistently in their relative contributions to differences among samples. To simplify analysis, the effect of exposure (for which there were no hypotheses about effects on composition of pigments) was excluded from subsequent univariate analysis of relative amounts of phycoerythrocyanin. Phycoerythrocyanin interacted strongly with all factors $\left(F_{12,192}=3.39, \mathrm{p}<\right.$ $0.001)$, but there were no clear patterns of differences.

Spectral matching indices showed differences in assemblages of micro-algae between Sydney and Brisbane (Fig. 5) and the significant alga $\times$ latitude interaction $\left(F_{1,523}=6.65, \mathrm{p}<0.05\right.$; Fig. 6$)$. At each latitude, spectral signatures of assemblages were more similar to those of cyanobacteria than to those of green micro-algae, but this was more marked in Sydney than in Brisbane (Fig. 6); spectra were never similar to assemblages of diatoms (not shown). There was also considerable variation between years, particularly in winter (Fig. 5). 
Table 1. Eight multivariate analyses (PERMANOVA; Anderson 2001), one for each period of sampling at each latitude, for relative amounts of pigments in samples of epilithic microphytobenthos from different exposures to waves (Wav; fixed, exposed versus sheltered), heights on the shore (He; fixed, 4 levels) and locations (Loc; random, 2 levels, nested in waves). Degrees of freedom differ among tests because of missing samples. Significant effects considered in the text are in bold

\begin{tabular}{|c|c|c|c|c|c|c|c|c|c|c|c|c|c|c|c|c|}
\hline & \multicolumn{8}{|c|}{ - Brisbane } & \multicolumn{8}{|c|}{ _ Sydney - } \\
\hline & \multicolumn{4}{|c|}{ _ Winter } & \multicolumn{4}{|c|}{ Summer } & \multicolumn{4}{|c|}{ - Winter } & \multicolumn{4}{|c|}{ Summer } \\
\hline & \multicolumn{2}{|c|}{ Year 1} & \multicolumn{2}{|c|}{ Year 2} & & \multicolumn{2}{|c|}{ Year 2} & \multicolumn{2}{|c|}{ Year 1} & \multicolumn{2}{|c|}{ Year 2} & \multicolumn{2}{|c|}{ Year 1} & \multicolumn{2}{|c|}{ Year 2} \\
\hline & $\mathrm{df}$ & $\mathrm{p}$ & $\mathrm{df}$ & $\mathrm{p}$ & df & $\mathrm{p}$ & df & $\mathrm{p}$ & df & $\mathrm{p}$ & df & $\mathrm{p}$ & $\mathrm{df}$ & $\mathrm{p}$ & $\mathrm{df}$ & $\mathrm{p}$ \\
\hline Wav & 1 & 0.001 & 1 & 0.26 & 1 & 0.001 & 1 & 0.001 & 1 & 0.04 & 1 & 0.13 & 1 & 0.34 & 1 & 0.34 \\
\hline $\mathrm{He}$ & 3 & 0.23 & 3 & 0.13 & 3 & 0.11 & 1 & 0.1 & 3 & 0.19 & 3 & 0.24 & 3 & 0.24 & 2 & 0.09 \\
\hline Loc(Wav) & 2 & 0.17 & 2 & 0.04 & 2 & 0.13 & 2 & 0.004 & 2 & 0.49 & 2 & 0.001 & 2 & 0.02 & 2 & 0.01 \\
\hline $\mathrm{Wav} \times \mathrm{He}$ & 3 & 0.32 & 3 & 0.11 & 3 & 0.22 & 1 & 0.49 & 3 & 0.28 & 3 & 0.31 & 3 & 0.32 & 2 & 0.18 \\
\hline $\mathrm{He} \times \operatorname{Loc}($ Wav $)$ & 6 & 0.04 & 6 & 0.24 & 6 & 0.15 & 2 & 0.001 & 6 & 0.006 & 6 & 0.001 & 6 & 0.001 & 4 & 0.04 \\
\hline Residual & 64 & & 32 & & 64 & & 16 & & 64 & & 64 & & 64 & & 48 & \\
\hline
\end{tabular}

\section{DISCUSSION}

Amounts of chl a were anticipated to be less in Brisbane than in Sydney as a consequence of hotter temperatures and greater insolation at lower latitudes. Cyanobacteria were expected to be relatively more abundant in hotter than in cooler conditions. Over all heights measured on the shore, there were, surprisingly, minimal effects of latitude on amounts of chl $a$, and assemblages of EMPB were dominated more strongly by cyanobacteria in Sydney than in Brisbane. As demonstrated previously (Underwood 1984c, Dye \& White 1991, Thompson et al. 2004) and for similar reasons to the anticipated effects of latitude, amounts of chl a were expected to be greater during winter than during summer. Our results are consistent with this seasonal pattern, except at the top of the shore, where there were few, if any, seasonal differences. Despite variability among shores, our data were, however, entirely consistent with the widespread pattern of increasing amounts of $\mathrm{chl} a$ at lower levels on the shore (see 'Introduction').

Patterns with height and season were not as clearcut as in some previous studies (Underwood 1984c, Thompson et al. 2005). This was true even though sampling here was extensive and there were numerous (often $>100$ ) degrees of freedom in analyses. The lack of clear trends was partially because of variability among the multiple shores sampled for each condition of region and wave exposure. Thompson et al. (2005) also showed differences in patterns of chlorophyll with height among shores of similar exposure to waves.

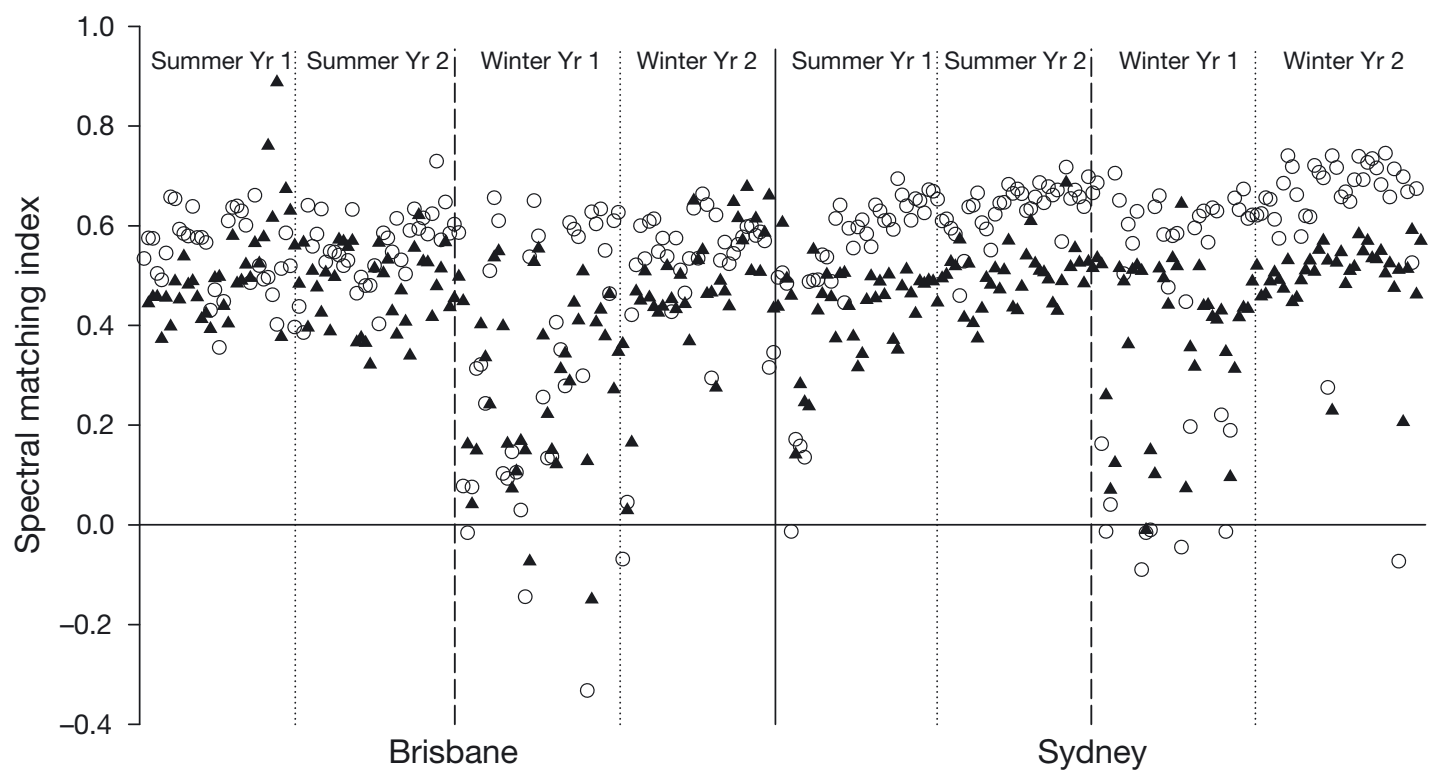

Fig. 5. Spectral matching indices (SIs) for each spectrum when compared with library spectra of cyanobacteria (O) or green microalgae $(\mathbf{\Lambda})$ at Brisbane or Sydney. If $\mathrm{SI}=1$, the spectra are a perfect match; if $\mathrm{SI}=0$, they have no similarity; negative values represent spectra that are mirror images of one another 
Seasonal effects on EMPB can be influenced by height on the shore, but how this happens can vary. For example, in the northern hemisphere, seasonal variation in differences in amounts of chl a between the top and bottom of the shore has been attributed to greater variation in amounts of EMPB on the upper shore, where stress during emersion was greater (e.g. Aleem 1950, Castenholz 1963, Thompson et al. 2004, 2005). In contrast, in the southern hemisphere, densities of EMPB on the upper shore varied little with season, and differences in chl a between heights were influenced more by changes in density lower on the shore (Australia: Underwood 1984c, present study; S. Africa: Dye \& White 1991). Castenholz (1963) and Hutchinson et al. (2006) have shown also that the aspect of the shore can affect the distribution of EMPB, but, in the present study, this is irrelevant because samples were collected only from near-horizontal patches of rock from gently sloping shores.

On the east coast of Australia, where macro-algal canopy is typically not present (except at low levels or in rockpools), we found that sheltered shores generally had more chl a than did exposed shores. This pattern was the opposite of that observed in Australia by MacLulich (1987), who found more chl a on exposed than on sheltered shores. Our pattern also differed from those observed in NW Europe. Jenkins \& Hartnoll (2001) also found more chl a at sheltered than at exposed locations, but this was on shores with macroalgal canopy, whereas our shores had no canopy. Where macro-algal canopy covaried with exposure, there was more chl $a$ on exposed than on sheltered shores (Thompson et al. 2005). Amounts of EMPB on

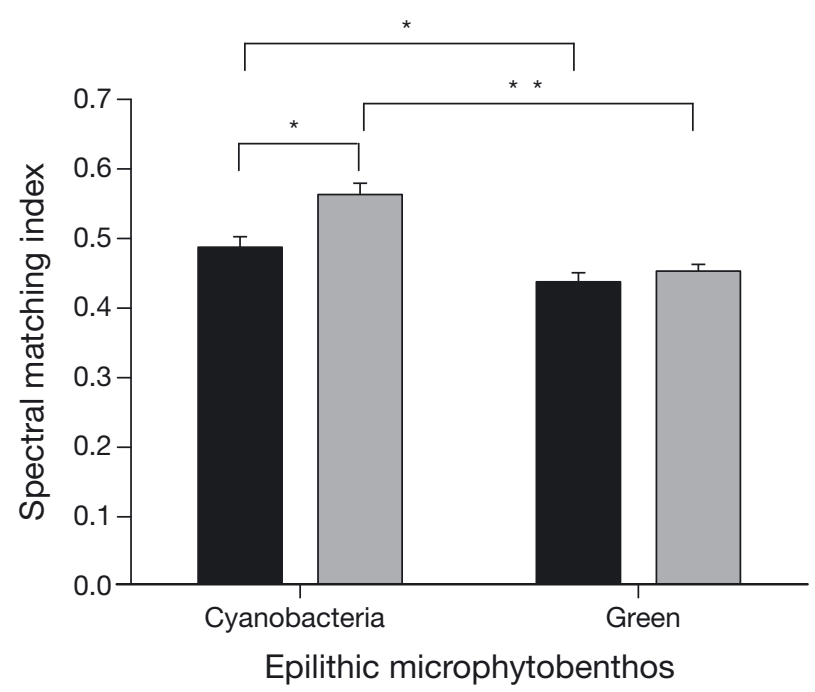

Fig. 6. Mean (SE) spectral matching indices for 2 types of epilithic microphytobenthos at subtropical (black bars: Brisbane) or temperate (grey bars: Sydney) latitudes. ${ }^{*},{ }^{* *}: \mathrm{p}<$ $0.05, \mathrm{p}<0.01$, respectively (Student-Newman-Keuls tests) shores that differ in exposure to waves may be influenced by the indirect effects of waves on the identity and density of grazers, in addition to the direct effects of the physical environment. Observed differences from studies elsewhere may be the consequence of the different assemblages of EMPB (i.e. dominated by cyanobacteria in Australia or diatoms, especially in winter in the northern hemisphere, e.g. Hill \& Hawkins 1991), the lack of canopy-forming macro-algae in Australia and/or annual variation in conditions. Specific reasons for the contrast with MacLulich's (1987) study in SE Australia were not apparent. There were no distinct effects of exposure on differences in amounts of chl a between the upper and lower shore.

There were also considerable differences in amounts of chl a between years, which may have been directly linked to relative differences in weather (which varied greatly) between years. Both latitudes had exceptionally cool and cloudy summers, with much greater than average precipitation during the summer of 2007/2008, possibly associated with the mature La Niña event at that time in the Pacific Ocean. Differences in the composition of assemblages of EMPB between latitudes that varied from year to year may also be implicated.

Existing literature does not indicate consistent patterns in composition of assemblages of EMPB among climatic regions in relation to environmental variables. In tropical Hong Kong, cyanobacteria were relatively more abundant during summer (Nagarkar \& Williams 1999). In Sydney, the cyanobacteria Anacystis were most abundant during winter and lower on the shore (MacLulich 1987). In Sydney, the variety of EMPB was greatest on the lower shore, during summer and under the most exposed conditions (MacLulich 1987). This was in contrast to many assemblages at temperate northern latitudes that were dominated by diatoms during winter (Castenholz 1963, Hill \& Hawkins 1991, Thompson et al. 2005), which were more abundant lower on the shore (Castenholz 1963) and decreased with increasing insolation (Thompson et al. 2004). In the UK, cyanobacteria can also be prevalent during the summer (Hill \& Hawkins 1991, Thompson et al. 2004, 2005). In the present study, assemblages of EMPB at each latitude were typically dominated by cyanobacteria, in agreement with MacLulich (1987) and Nagarkar \& Williams (1999). Spectral matching analyses did, however, demonstrate a clear interaction between composition of pigments and latitude, in addition to strong inter-annual variation. Spectral samples from temperate shores in Sydney were more similar to cyanobacteria than were those found near subtropical Brisbane. Given the hotter climate in Brisbane and the tendency for cyanobacteria to be tolerant of and more prevalent in extreme insolation and temperatures 
(Nagarkar \& Williams 1999), this was somewhat surprising. Our correlations between amounts of chl $a$ and values for climatic variables in the month prior to sampling provide some indication that extreme events (highest temperatures) were perhaps more important than mean conditions (mean maximal temperature or mean daily solar exposure) for densities of micro-algae (see 'Results; Temperature and insolation').

Some of the patterns observed in EMPB may have been due to variation in recruitment or succession among different levels of the experimental factors. For example, recolonisation might be expected to be faster low on the shore at cooler latitudes during winter than elsewhere. Previous studies in the region suggest that recolonising assemblages of EMPB are stable after 4 wk (Underwood 1984c, MacLulich 1986, Murphy et al. 2006), but this did not appear to be the case for the first sampling occasion in the present study, when amounts of EMPB were considerably less than expected. Subsequently, longer times (6 to $8 \mathrm{wk}$ ) for recolonisation were allowed between scrubbing and sampling. After this time, amounts of EMPB were within the range expected for the region (see 'Results; Amounts of chl $\mathrm{a}^{\prime}$ ). For some treatments, however, assemblages may still have been at some intermediate stage of succession. Allowing periods of time $>8 \mathrm{wk}$ greatly increased the risk of colonisation by macroalgae with the consequent swamping of signals from EMPB and loss of samples.

Differences in distributions, abundances and types of EMPB may also be explained by differential consumption by grazers. Amounts of EMPB at different heights on the shore (including some locations sampled in the present study) were not related to differences in densities of grazers (Underwood 1984c, Jenkins et al. 2001). Selective grazing can also alter the relative abundance of types of EMPB (e.g. Calow 1973, Nicotri 1977, Hill \& Hawkins 1991). Near Sydney, there was no tendency for types of EMPB to be consumed by the limpet Cellana tramoserica, in proportions different from those on natural substrata (MacLulich (1983). The snail Bembicium nanum does, however, show differential effects (Murphy \& Underwood 2006). Thus, quantities of biofilm differed little, but there were seasonal differences in the types of EMPB between Sydney and Brisbane that could be attributable to local conditions or to different assemblages of grazers.

Many of the important grazing gastropods are common to both regions, but shores near Sydney supported far greater densities of grazers than did shores near Brisbane (Endean et al. 1956 versus Underwood 1975). To be sufficient to support greater densities of grazers, production by EMPB may be much greater in Sydney than in Brisbane. Increasing temperatures in Sydney may decrease production, thus indirectly reducing densities of grazers, but not cause any observable change in standing stocks. Changes in amounts of EMPB that may be caused by changing climatic conditions are far from clear.

Large inter-annual variation in the direction and magnitude of patterns observed in the present study emphasises the importance of having measurements from multiple years before reliable conclusions can be drawn about differences among variables and the potential effects of climatic change. Trends (and their underlying causes) observed here differ from those in other studies, indicating that patterns in EMPB cannot always be extrapolated to different locations. Changing climate, particularly increases in maximal temperatures, may cause changes in production by and types of EMPB. The current situation in subtropical areas near Brisbane suggests that any long-term responses to increased temperature on rocky shores in Sydney may not cause changes in the amounts of EMPB. Further work is needed to determine what may happen to densities of grazers that are substantially smaller around Brisbane, where the animals are largely confined to shelter in pools and crevices (authors' unpubl. data). Greater wave action associated with the increasing frequency of storms may reduce amounts of EMPB in the future. Additional, longer term studies, with finer scale temporal resolution are required, if we are to understand clearly how EMPB responds to environmental conditions. These will undoubtedly shed more light on the consequences of climatic change for intertidal ecology.

Acknowledgements. The present study was supported by funds from the Australian Research Council through the Centre for Research on Ecological Impacts of Coastal Cities (EICC) and ARC Discovery Projects. We thank Jabin Watson, Mel Langridge, Renee Rossini and the staff at EICC for help in the field, and Craig Myers for assistance in processing digital data. We also thank 4 anonymous reviewers and the editor for improvements to the manuscript. This work conforms to the policies on ethics in research of the University of Sydney and of the EICC.

\section{LITERATURE CITED}

Aleem AA (1950) Distribution and ecology of British marine littoral diatoms. J Ecol 38:75-106

Anderson MJ (2001) A new method for non-parametric multivariate analysis of variance. Austral Ecol 26:32-46

> Bustamante RH, Branch GM, Eekhout S, Robertson B and others (1995) Gradients of intertidal primary productivity around the coast of South Africa and their relationships with consumer biomass. Oecologia 102:189-201

> Calow P (1973) Food of Ancylus fluviatilis (Mull), a littoral stone-dwelling, herbivore. Oecologia 13:113-133

> Castenholz RW (1961) Effect of grazing on marine littoral diatom populations. Ecology 42:783-794

Castenholz RW (1963) An experimental study of the vertical distribution of littoral marine diatoms. Limnol Oceanogr 8: $450-462$ 
Clarke KR, Warwick RM (2001) Change in marine communities: an approach to statistical analysis and interpretation. PRIMER-E, Plymouth

CSIRO (Commonwealth Science and Industrial Research Organisation) (2007) Climate change in Australia: technical report, Chapter 5. Regional climate change projections. CSIRO, Aspendale

Dye AH, White DRA (1991) Intertidal microalgal production and molluscan herbivory in relation to season and elevation on two rocky shores on the east coast of southern Africa. S Afr J Mar Sci 11:483-489

Endean R, Kenny R, Stephenson W (1956) The ecology and distribution of intertidal organisms on the rocky shores of the Queensland mainland. Aust J Mar Freshw Res 7: 88-146

Haven SB (1973) Competition for food between intertidal gastropods Acmaea scabra and Acmaea digitalis. Ecology 54:143-151

Hawkins SJ, Hartnoll RG (1983) Grazing of intertidal algae by marine invertebrates. Oceanogr Mar Biol Annu Rev 21: 195-285

- Hawkins SJ, Watson DC, Hill AS, Harding SP, Kyriakides MA, Hutchinson S, Norton TA (1989) A comparison of feeding mechanisms in microphagous, herbivorous, intertidal, prosobranchs in relation to resource partitioning. J Molluscan Stud 55:151-165

Hawkins SJ, Hartnoll RG, Kain JM, Norton TA (1992) Plant-animal interactions on hard substrata in the Northeast Atlantic. In: John DM, Hawkins SJ, Price JH (eds) Plant-animal interactions in the marine benthos. Oxford University Press, Oxford, p 1-32

Hill AS, Hawkins SJ (1990) An investigation of methods for sampling microbial films on rocky shores. J Mar Biol Assoc UK 70:77-88

Hill AS, Hawkins SJ (1991) Seasonal and spatial variation of epilithic microalgal distribution and abundance and its ingestion by Patella vulgata on a moderately exposed rocky shore. J Mar Biol Assoc UK 71:403-423

Hutchinson N, Nagarkar S, Aitchison JC, Williams GA (2006) Microspatial variation in marine biofilm abundance on intertidal rock surfaces. Aquat Microb Ecol 42:187-197

IPCC (Intergovernmental Panel on Climate Change) (2007) Climate change 2007: synthesis report. In: Pachauri RK, Reisinger A (eds) Contribution of Working Groups I, II and III to the 4th assessment report of the Intergovernmental Panel on Climate Change. IPCC, Geneva, p 104

> Jackson AC, Murphy RJ, Underwood AJ (2009) Patiriella exigua: grazing by a starfish in an overgrazed intertidal system. Mar Ecol Prog Ser 376:153-163

Jeffrey SW, Mantoura RFC, Wright SW (eds) (1997) Phytoplankton pigments in oceanography: guidelines to modern methods. Monographs on oceanographic methodology, Vol 10. UNESCO Publishing, Paris

> Jenkins SR, Hartnoll RG (2001) Food supply, grazing activity and growth rate in the limpet Patella vulgata L.: a comparison between exposed and sheltered shores. J Exp Mar Biol Ecol 258:123-139

> Jenkins SR, Arenas F, Arrontes J, Bussell J and others (2001) European-scale analysis of seasonal variability in limpet grazing activity and microalgal abundance. Mar Ecol Prog Ser 211:193-203

Kaehler S, Froneman PW (2002) Herbivore-mediated increase in the photosynthetic capacity of marine biofilms: indirect effects of changing microalgal assemblage composition. Mar Ecol Prog Ser 234:15-22

Keough MJ, Raimondi PT (1995) Responses of settling invertebrate larvae to bioorganic films: effects of different types of films. J Exp Mar Biol Ecol 185:235-253
Keough MJ, Raimondi PT (1996) Responses of settling invertebrate larvae to bioorganic films: effects of large-scale variation in films. J Exp Mar Biol Ecol 207:59-78

Kirkpatrick GJ, Millie DF, Moline MA, Schofield O (2000) Optical discrimination of a phytoplankton species in natural mixed populations. Limnol Oceanogr 45:467-471

MacLulich JH (1983) Aspects of the ecology of intertidal epilithic microflora at Green Point, New South Wales. MSc thesis, University of Sydney, Sydney

MacLulich JH (1986) Colonization of bare rock surfaces by microflora in a rocky intertidal habitat. Mar Ecol Prog Ser 32:91-96

MacLulich JH (1987) Variations in the density and variety of intertidal epilithic microflora. Mar Ecol Prog Ser 40: 285-293

> Mak YM, Williams GA (1999) Littorinids control high intertidal biofilm abundance on tropical, Hong Kong rocky shores. J Exp Mar Biol Ecol 233:81-94

Murphy RJ, Underwood AJ (2006) Novel use of digital colourinfrared imagery to test hypotheses about grazing by intertidal herbivorous gastropods. J Exp Mar Biol Ecol 330:437-447

> Murphy RJ, Tolhurst T, Chapman MG, Underwood AJ (2004) Estimation of surface chlorophyll on an exposed mudflat using digital colour-infrared (CIR) photography. Estuar Coast Shelf Sci 59:625-638

> Murphy RJ, Underwood AJ, Pinkerton MH, Range P (2005) Field spectrometry: new methods to investigate epilithic micro-algae on rocky shores. J Exp Mar Biol Ecol 325: 111-124

Murphy RJ, Underwood AJ, Pinkerton MH (2006) Quantitative imaging to measure photosynthetic biomass on an intertidal rock-platform. Mar Ecol Prog Ser 312:45-55

Murphy RJ, Underwood AJ, Jackson AC (2009) Field-based remote sensing of intertidal epilithic chlorophyll: techniques using specialized and conventional digital cameras. J Exp Mar Biol Ecol 380:68-76

Nagarkar S, Williams GA (1999) Spatial and temporal variation of cyanobacteria-dominated epilithic communities on a tropical shore in Hong Kong. Phycologia 38:385-393

> Nicotri ME (1977) Grazing effects of four marine intertidal herbivores on microflora. Ecology 58:1020-1032

> Ruban AV, Horton P (1995) Regulation of nonphotochemical quenching of chlorophyll fluorescence in plants. Aust $\mathrm{J}$ Plant Physiol 22:221-230

Savitzky A, Golay MJE (1964) Smoothing and differentiation of data by simplified least squares procedures. Anal Chem 36:1627-1639

Skov MW, Volkelt-Igoe M, Hawkins SJ, Jesus B, Thompson RC, Doncaster CP (2010) Past and present grazing boosts the photo-autotrophic biomass of biofilms. Mar Ecol Prog Ser 401:101-111

Steinier J, Termonia Y, Deltour J (1972) Comments on smoothing and differentiation of data by simplified least square procedure. Anal Chem 44:1906-1909

- Steneck RS (1982) A limpet-coralline alga association: adaptations and defenses between a selective herbivore and its prey. Ecology 63:507-522

> Thompson RC, Norton TA, Hawkins SJ (1998) The influence of epilithic microbial films on the settlement of Semibalanus balanoides cyprids - a comparison between laboratory and field experiments. Hydrobiologia 375/376: 203-216

> Thompson RC, Tobin ML, Hawkins SJ, Norton TA (1999) Problems in extraction and spectrophotometric determination of chlorophyll from epilithic microbial biofilms: towards a standard method. J Mar Biol Assoc UK 79: $551-558$ 
Thompson RC, Norton TA, Hawkins SJ (2004) Physical stress and biological control regulate the producer-consumer balance in intertidal biofilms. Ecology 85:1372-1382

Thompson RC, Moschella PS, Jenkins SR, Norton TA, Hawkins SJ (2005) Differences in photosynthetic marine biofilms between sheltered and moderately exposed rocky shores. Mar Ecol Prog Ser 296:53-63

Underwood AJ (1975) Intertidal zonation of prosobranch gastropods: analysis of densities of four coexisting species. J Exp Mar Biol Ecol 19:197-216

Underwood AJ (1979) The ecology of intertidal gastropods. Adv Mar Biol 16:111-210

Underwood AJ (1984a) Microalgal food and the growth of the intertidal gastropods Nerita atramentosa Reeve and Bembicium nanum (Lamarck) at four heights on a shore. J Exp Mar Biol Ecol 79:277-291

Underwood AJ (1984b) Vertical and seasonal patterns in competition for microalgae between intertidal gastropods. Oecologia 64:211-222

Editorial responsibility: Brian Helmuth, Columbia, South Carolina, USA
Underwood AJ (1984c) The vertical-distribution and seasonal abundance of intertidal microalgae on a rocky shore in New South Wales. J Exp Mar Biol Ecol 78: 199-220

Underwood AJ, Murphy RJ (2008) Unexpected patterns of facilitatory grazing revealed by quantitative imaging. Mar Ecol Prog Ser 358:85-94

Underwood AJ, Denley EJ, Moran MJ (1983) Experimental analyses of the structure and dynamics of mid-shore rocky intertidal communities in New South Wales. Oecologia 56: 202-219

Wieczorek SK, Todd CD (1998) Inhibition and facilitation of settlement of epifaunal marine invertebrate larvae by microbial biofilm cues. Biofouling 12:81-118

Yallop ML, Winder BD, Paterson DM, Stal LJ (1994) Comparative structure, primary production and biogenic stabilization of cohesive and non-cohesive marine sediments inhabited by microphytobenthos. Estuar Coast Shelf Sci 39: $565-582$

Submitted: December 9, 2009; Accepted: June 30, 2010 Proofs received from author(s): October 17, 2010 